\section{Pesticide perspective}

ANOTHER shot was fired last week in the long-raging battle between two of the main schools of thought on the balance to be struck between solutions to the world food problem and their environmental consequences.

Dr Cleve Goring, the director of research and development in plant science for the American-based conglomerate Dow Chemical, nailed his colours firmly to the mast when he spoke at the British Insecticide and Fungicide Conference, held in Brighton.

The three-fold increase in world food production needed by the end of the century to feed the world, he said, would probably require a five-fold increase in the use of pesticides. But he warned that pesticides would, along with other agricultural aids, only help to buy time, rather than solve the longterm food problem.

Dr Goring further warned that "extremists" in the "environmental movement and medical research establishment", especially in the United States, would cause the "unjustifiable elimination" of many products now in use from which the future demand for pesticides would primarily be met. They had to "develop some perspective on the largely imaginary horror of a 'Silent Spring' and the minute amounts of pesticide chemicals that occur in our food".

In speaking out so strongly, Dr Goring drew attention to the apparently increasing plight of even the largest chemical companies engaged in pesticide production. There is evidence that work on new pesticides is being cut not simply as a result of the effects of the recession on research and development but also because the returns are too low for other reasons.

It is accepted even by some environmentalists that the balance is wrong between the time it now takes to develop a new product and the period that the patent laws last. Moreover, it has now become apparent that the new products least likely to yield an economic return are actually the safest in environmental terms because they are also the most selective in their effects.

Dr Goring referred to these matters when he outlined four problems of special concern in the development and use of pesticides:

- The excessive time required in some countries to bring a product from the discovery stage to the market place.

- The need for a "benchmark system" to evaluate the environmental acceptability of new pesticides.

- The lack of agreement between countries on uniform test procedures and tolerances.

- The lack of a workable policy for products reputed to be carcinogenic.
On the increasingly difficult problem of carcinogenicity, Dr Goring had a sharp word for the US Environmental Protection Agency (EPA). He described its recent list of cancer principles as "perhaps the most serious problem", and pointed out that a published list of suspected carcinogens included "many of the natural materials essential to living systems".

But given Dow Chemical's place in the market-sales of pesticides and consumer products last year accounted for more than $10 \%$ of its total sales of almost $\$ 5,000$ million, making it the eighth largest chemical company in the world-Dr Goring's concern was naturally with what he called "over-regulation" of pesticides, which had advanced "beyond all reason".

He was reflecting the view of those who believe that the chances of further chemical breakthroughs were now being reduced. But this view seems to be about as widespread as the environmentalists' belief that there are enough pesticides in existence already. Between the two, however, is an even more widely argued contention that it is not so much the pesticides themselves which are dangerous as the manner in which they are used. As one expert put it last week, "people need not be against their use, only against dangerous substances carelessly used".

\section{Nuclear deals proliferate}

THE path towards nuclear non-proliferation is tortuous and often contradictory. This was revealed again recently when more nuclear deals involving less developed countries were announced at about the same time as further meetings of the Nuclear Supplies Group took place in London.

The group, whose members include most of the world's nuclear countriesthe USA, the USSR, the UK, France, West Germany, Canada and Japanwishes to prevent the use of fissile waste products for the manufacture of nuclear weapons. But some of its members are also solidly encouraging the use of nuclear power outside their own privileged circle.

In recent months deals have been reported between France and South Korea for a plutonium separation plant, and between West Germany and Brazil for complete nuclear systems including fuel reprocessing. Secret dealings between West Germany and South Africa have also been brought to light.

Now the UK has joined at least six other countries, including Australia and South Africa, which are interested in Iran's ambitious nuclear programme, and has announced a dual agreement that offers both training and technical assistance, but no reactors.

And the United States apparently promised Egypt two nuclear power reactors, for use in desert desalination plants, during President Sadat's visit to Washington earlier this month. At the same time, the influential Cairo newspaper $A l$ Ahram reported that it was Egypt's intention to build 10 nuclear power stations during the next 20 years.

Large as it is, the Egyptian programme barely holds a proverbial candle to that planned in Iran, where the general aim is to make nuclear power the prime source of energy in the country by the $1990 \mathrm{~s}$. This will involve some 20 reactors with a combined capacity of around $23,000 \mathrm{MW}$ more than double Egypt's proposed $10,000 \mathrm{MW}$, which is its target for the year 2000 .

Fears that Iran may be tempted to establish itself as a full nuclear power have not yet manifested themselves as they have over Egypt's plans, in spite of the stimulus that India's nuclear explosion obviously gave to the Shah. The Middle East situation, where Israel's nuclear potential has increased, looms larger in the diplomatic mind, as $\mathrm{Dr}$ Kissinger implied when he quickly confirmed that an acceptable arrangement to safeguard the security of the by-products had been worked out with Egypt.

The issue is clearly important to the Nuclear Suppliers Group. The British Foreign Secretary, Mr James Callaghan, emphasised the matter at the UN in September, pronouncing that "the statesmen of the world have a moral duty to act before it is too late to work out the means of controlling the nuclear threat". The talks in London, in fact, were apparently convened in order to discuss the proposals he had made in the General Assembly.

In the meantime, however, the nuclear countries continue to deal among themselves. The British Nuclear Power Company has signed an "enabling agreement" with the Soviet Union on the exchange of experience, techniques and possibly materials connected with the so-called 'steamer' reactors due to come into operation in the UK in the 1980 s but already working there. And the efforts to bring Canada's successful technology to the UK continue.

There is evidence of increasing resistance within the nuclear countries to the elaborate nuclear power programmes at home. But so far nothing similar has revealed itself in countries wanting such programmes. Only the Nuclear Suppliers Group is showing signs of concern. But it is only the Nuclear Suppliers Group that is acting to satisfy those wants. 